\title{
AN AMERICAN SPECIES OF SOLENOPSIA
}

\author{
By Charles T. Brues
}

\section{Biological Laboratories, Harvard University}

The genus Solenopsia was first described by Wasmann in 1899 to include a very peculiar subapterous species of Diapriidæ from Europe. This extremely minute insect, found in nests of the thief ant, Solenopsis fugax, in Holland, France, and Italy is exceedingly ant-like in form, even to the development of a scale-like node on the dorsal face of the abdominal petiole. Of this species Wasmann knew only the female, but the male of a second species, S. castanea, has been since described by Kieffer from the Pyrenees in Southern France where it lives in nests of Solenopsis geminata. ${ }^{1}$ Like the female, the male is practically wingless, but the antennæ are not so strongly clavate.

Solenopsia differs from all other Diapriidæ in the form of the abdominal petiole which is developed into an elevated node like that found only in certain ants, although it resembles that of a formicine or dolichoderine rather than that of a myrmicine ant, and the host with which it has been found in Europe is one of the Myrmicinæ.

Last summer I received from Professor C. H. Kennedy of Ohio State University several very beautifully executed pencil sketches of a minute strange hymenopterous insect that had been found in a nest of Prenolepis parvula in eastern Tennessee by Professor Clyde Dennis of Tusculum College. These sketches indicated that it was either a diapriid like Solenopsia or perhaps an aberrant embolemid.

At Professor Kennedy's suggestion I have since examined the specimen and it proves without question to be a species of Solenopsia, the first to be discovered in the New World.

It is closely similar to the European forms but the resemblance between the abdominal petiole and that of its host is

\footnotetext{
${ }^{1}$ Wasmann cites it as a guest of this ant, although Kieffer gives $S$. fugax as the host ant.
} 
much closer than that of the Old World species to their myrmicine hosts.

The new species is described below, illustrated by several figures drawn by Mrs. A. S. O'Connor. The latter are to a great extent based on Dr. Kennedy's very excellent sketches which he placed at our disposal.

Solenopsia Wasmann.

Zoologica, Heft 26, p. 171 (1899).

Solenopsia americana sp. nov. (Fig. 1)

o. Length $1.3 \mathrm{~mm}$. Black; the thorax and abdominal petiole light reddish brown; the abdomen stained with brown below on the sides basally and pale at extreme tip; legs and antennæ more yellowish than the thorax. Head smooth and shining; the eyes small, rounded, placed well forward on the sides of the head at about the middle; ocelli small, in a small equilateral triangle. Antennæ 11-jointed, inserted above a very narrow shelf at the level of the eyes; scape long, nearly as long as the head, curved and much thicker toward apex; pedicel longer than wide, about onefourth as long as the scape; first flagellar joint much narrower than the pedicel, especially at the base; following six joints gradually wider and of about equal length, each shorter than the pedicel; last three joints forming a large, abrupt club, the basal joint narrowed at base, the second widest and the third longest. Seen in profile the head is evenly arcuate above and the long, sharply receding face forms a straight line above, curving inward toward the mouth; mandibles small, more or less triangular and apparently pointed at apex. Pronotum short at the median line, but extending back to the tegulæ as a broad lateral band on each side of the mesonotum; scutellum separated by a very fine transverse basal suture, its posterior narrowed portion convex, with the basal impression single, with each side bent posteriorly in the form of a broad, inverted crescent; propodeum much narrowed above with the apex sharply widened and concave behind to form two backwardly directed arms which encircle the sides of the abdominal petiole when the latter is turned upwards, these arms more or less acute apically. Upper surface of abdominal petiole 
steeply sloping forwards, about twice as long as wide, the petiole much broader below; the sides moderately woolly. Second segment occupying nearly two-thirds the length of the abdomen; following tergites short, slightly decreasing
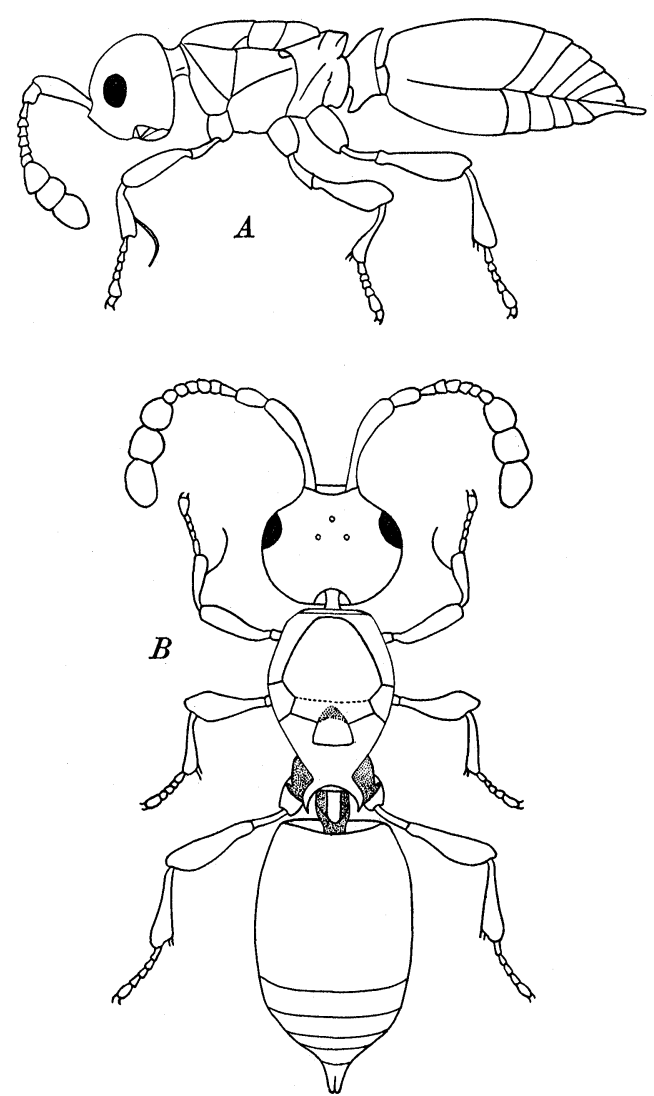

Fig. 1. Solenopsia americana sp. nov. $a$, lateral view; $b$, dorsal view.

in length apically. Ovipositor short, with two short, rather broad valves when seen from above. Legs moderately stout, the trochanters very long; all the femora and tibiæ clavate, the front tibia with a very long, curved spur arising well be- 
fore the apex. Wings preserved as vestiges; neither fore wing present in the type, but one very small hind wing remains attached as an oval, apparently complete wing with a costal vein-like thickening, this wing reaching about to the tip of the propodeum.

Type from Eastern Tennessee, collected in a nest of Prenolepis parvula Mayr, by Professor Clyde Dennis. The type is in the collection of the Ohio State University, Columbus, Ohio.

There is another genus in North America which is very similar to Solenopsia. This is Auxopædeutes first discovered by Professor W. M. Wheeler as a guest of Solenopsis molesta near Austin, Texas and described by the present writer in 1903. ${ }^{2}$ Later, I found a second species in Eastern Massachusetts also in a nest of Solenopsis molesta. ${ }^{3}$ Auxopædeutes differs from Solenopsia in having twelve joints in the antennæ and by the less modified petiolar segment of the abdomen. The latter is slightly raised dorsally, but does not rise scale-like as in Solenopsia and its rounded dorsal boss lies under and not between the propodeal processes. In both species of Auxopædeutes the wings are completely absent and not represented by vestiges.

Still another genus, Trimicrops Kieffer should be compared with Solenopsia. Kieffer placed this in the Calliceratidæ $æ^{4}$ although it differs from all members of that family in the form of the head and insertion of the antennæ on a shelf far above the clypeus as in the Diapriidæ. I have never seen specimens of Trimicrops, but suspect very strongly that it also is a diapriid, quite similar to the genera discussed above.

2Trans. American Entom. Soc., vol. 29, p. 126.

${ }^{3}$ Bull. Wisconsin Nat. Hist. Soc., vol. 8, p. 82 (1910).

${ }^{4}$ Ann. Soc. Sci. Bruxelles, vol. 30, p. 16 (1906) and also Das Tierreich, Lief, 42, p. 127 (1914). 

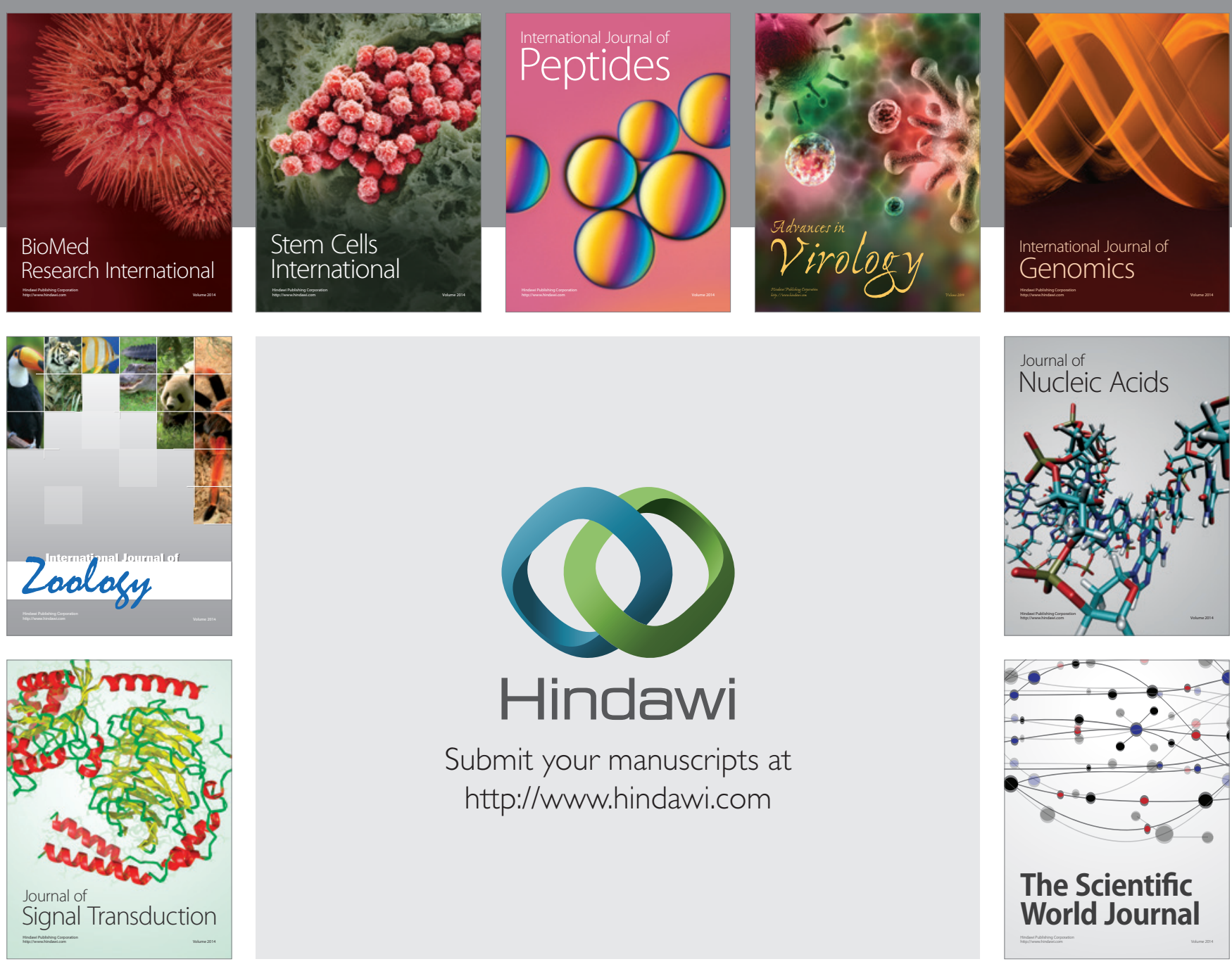

Submit your manuscripts at

http://www.hindawi.com
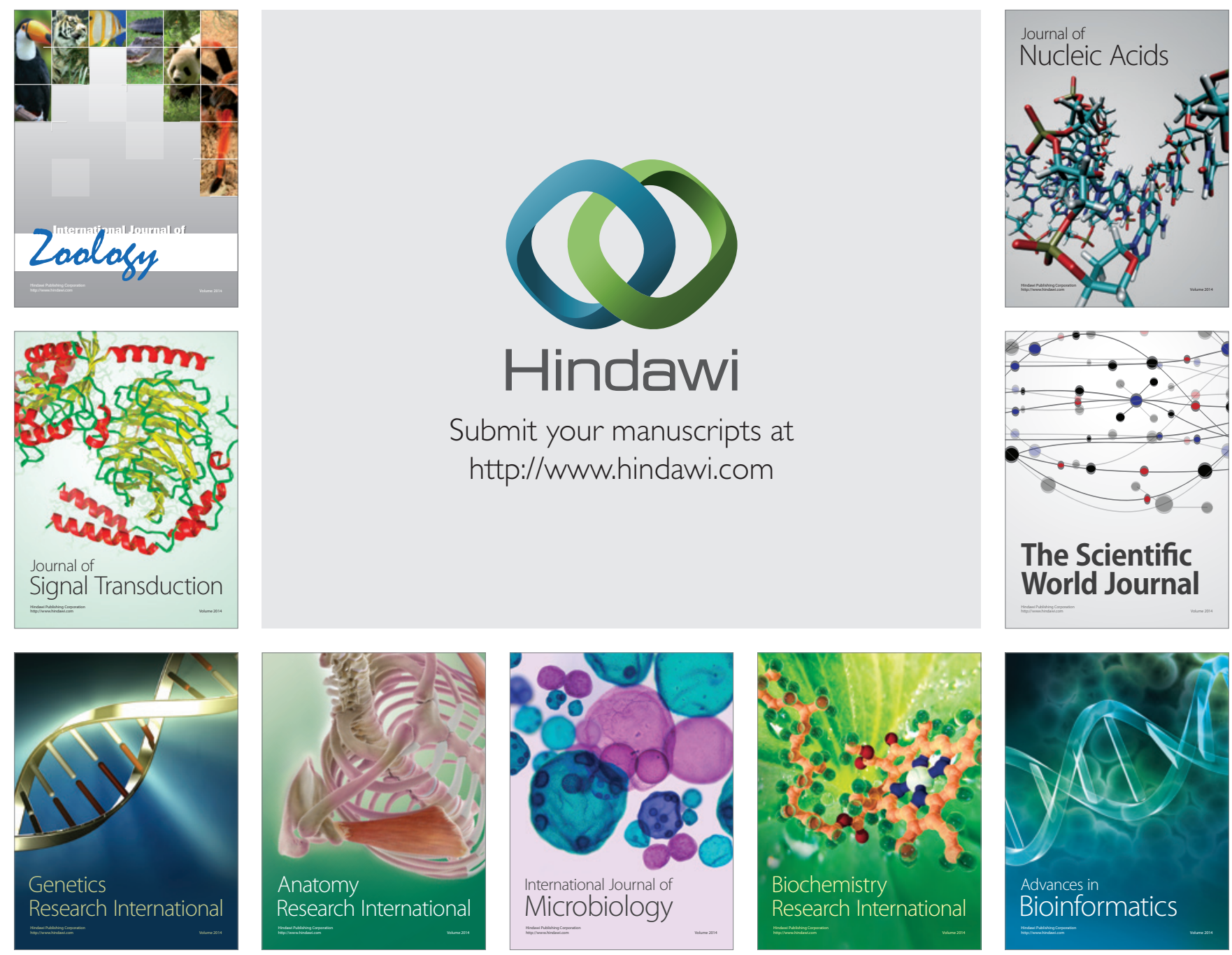

The Scientific World Journal
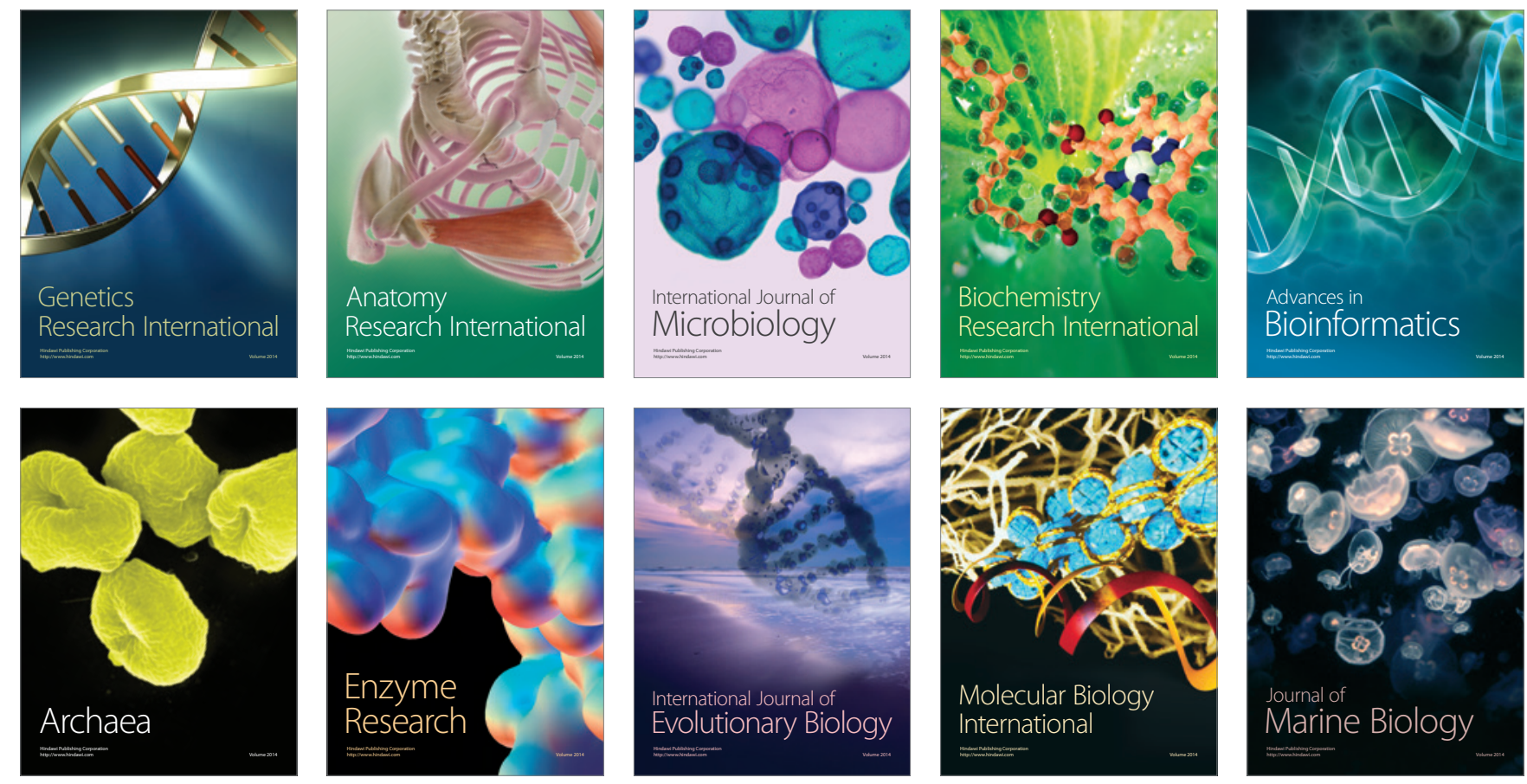